\title{
The effect of aquatic exercise program on low-back pain disability in obese women
}

\author{
Fariba Hossein Abadi* , Mohansundar Sankaravel, Fairus Fariza Zainuddin, Gunathevan Elumalai, Azira Iqlima Razli \\ Department of Sports Rehabilitation, Faculty of Sports Science and Coaching, Sultan Idris Education University (UPSI), Tanjung Malim, Malaysia
}

Low-back pain (LBP) is one of the most current causes to reduce work performance, limit daily activities and raising health cost, and it is increasing as obesity growing as a public health concern. While obese LBP people cannot avoid weight load on the spine in any exercise, they can easily carry out exercise in water. This study aimed to investigate the effect of aquatic exercise on LBP disability among obese women. In this study, a total of 39 women with body mass index $(\mathrm{BMI}) \geq 27 \mathrm{~kg} / \mathrm{m}^{2}$ who suffering from nonspecific chronic LBP were purposively selected. They randomly assigned in two groups; aquatic and control. The aquatic group carried out aquatic exercise, twice per week, 60 min per session, for 12 weeks. LBP disability was measured using modified Oswestry questionnaire with ten sections; pain intensity, personal care, lifting, walking, sitting, standing, sleeping, social life, traveling, and em- ployment. Results showed no significant difference in age, weight, BMI, waist to hip ratio, and percentage of body fat in both groups. An analyzing of multivariate analysis of covariance revealed that there was significant improvement on pain intensity, personal care, sitting, standing, sleeping, employment and total disability score in aquatic group, while there was no significant difference in lifting, walking, social life, and traveling abilities after 12 weeks between the groups. As a conclusion, this progressive aquatic exercise was a convenience and effective intervention program to reduce pain intensity, and improve personal care, sitting, standing, sleeping, and employment abilities in obese LBP women.

Keywords: Aquatic exercise, Low-back pain, Disability, Obese women

\section{INTRODUCTION}

Low-back pain (LBP) as a common health problem is extremely prevalent in many groups of population. According to global burden (GBD) LBP is currently related to impairment and activity limitation and subsequently leading work absence throughout much of the world (Hoy et al., 2010). It was estimated that LBP is widespread between $10 \%-63 \%$ with a median of $37 \%$ in several studies (Lonik et al., 2017). It is documented that more than $80 \%$ of the population will experience an episode of LBP during a period of their lives, which increases health care cost for the societies (Freburger et al., 2009). In addition, many studies showed the use of health care services for chronic LBP has increased substantially over the past two decades (Lonik et al., 2017).

Even though several environmental, occupational and personal factors influence the onset of LBP, obesity or high BMI $\left(<28 \mathrm{~kg} / \mathrm{m}^{2}\right)$ is known as one of cause of its occurrence (Shiri et al., 2010). On the other hand, since patients who suffer from LBP have periods of rest when their symptoms become worse, it often leads to weight gain and resulted in weakened muscles. It exclusively can affect the ventral and dorsal muscles of the trunk and reduce function of the spine (Lahiri et al., 2005). Then while several therapeutic strategies recommend rest and more limitation in physical function, increasing body fat mass or obesity is side effects of LBP (Irandoust and Taheri, 2015). Indeed, therapeutic suggestion is a paradox to take rest and decrease the physical activities while resting will make the patient gain more weight and become obese.

For that reason, recently a guideline for the supervision of nonsignificant chronic LBP patients, exercise therapy has been recommended as a first-line treatment for the reduction of pain and disability (Cuesta-Vargas et al., 2012; Gordon and Bloxham, 2016). Meanwhile, the evidence though revealed that a variety of exercise
${ }^{*}$ Corresponding author: Fariba Hossein Abadi

(iD) https://orcid.org/0000-0001-9273-2572

Department of Sports Rehabilitation, Faculty of Sports Science and Coaching,

Sultan Idris Education University, Tanjong Malim, 35900, Perak, Malaysia

E-mail: fariba@fsskj.upsi.edu.my

Received: October 20,2019 / Accepted: November 20, 2019
This is an Open Access article distributed under the terms of the Creative Commons Attribution Non-Commercial License (http://creativecommons.org/licenses/by-nc/4.0/) which permits unrestricted non-commercial use, distribution, and reproduction in any medium, provided the original work is properly cited. 
therapies to improve strengthening and fitness for the weakened stabilizing muscles of the spine, it is difficult for LBP sufferers to avoid the weight load on their spine in most types of exercises (Waller et al., 2009). Therefore, one effective form of exercises, according the gait control theory, is aquatic exercises due to the low-impact property of underwater fitness (Bender et al., 2005; Louw et al., 2016).

In the past two decades, aqua aerobic exercise or water-based exercise has become an alternative exercise program to achieve fitness and rehabilitation purposes for individuals who physically had difficulty in exercising on land (Delevatti et al., 2015). Additionally, water-based exercise is harmless and safer than land-based exercise to diminish the risk of injuries and difficulty of exercise (Hossein Abadi et al., 2017). It should outstanding that aquatic exercise not only capable to immerse the body in water and weigh up to $90 \%$ less than on land (Piotrowska-Calka, 2010), it can be an effective treatment for obese people with LBP who have difficulty with weight-bearing once doing physical exercise on land (Gordon and Bloxham, 2016; Irandoust and Taheri, 2015). According to Shiri et al. (2010) women are more associated with overweight or obesity since hormone alteration, changes in pain sensitivity and the differences in the distribution of body fat mass or to proportion of lean body mass, which could be lead to LBP (Shiri et al., 2010).

Thus, in spite of the fact that LBP sufferers are not able to bear the weight on spine during exercise on land, they can carry out exercises in water without worrying about the spinal pressure. Therefore, since improvement of LBP disability is a key issue in public health (Ionescu et al., 2013), it is a need to discover the effect of aquatic exercise on improvement of nonsignificant chronic LBP disability for women who have a vital role in the provision of health.

However, it is unclear if aquatic exercise amends the pain intensity and disability in obese women who are suffering from chronic nonsignificant LBP. Hence, this study aimed to investigate the effect of 12 weeks of aquatic exercise; $60 \mathrm{~min}$, two sessions a week on LBP disability and the related sections (pain intensity, personal care, lifting, walking, sitting, standing, sleeping, social life, traveling, and employment/homemaking) in obese women with BMI $\geq 27 \mathrm{~kg} / \mathrm{m}^{2}$. This study was an effort to be an eye-opener for obese women who suffering from nonsignificant LBP to relief their pain intensity and improve the related disability through aquatic exercise as a convenience exercise.

\section{MATERIALS AND METHODS}

This study was a randomized control trail with receiving an intervention program. The participants were obese women with nonsignificant chronic LBP. A total of 57 volunteer participants were recruited. Based on the inclusion criteria 39 participants were finally included for this study. The inclusion criteria were obese participants (BMI $\geq 27 \mathrm{~kg} / \mathrm{m}^{2}$ ) those who have clinically diagnosed with nonsignificant LBP problems more than 6 months and without any intervention procedures. Exclusion criteria included the lower BMI, surgery, cardiorespiratory health problem, water phobia or any other contraindication for aquatic exercise, and inability to safely enter and exit the pool. Following ethical approval (UPSI/PPPI/PYK/645), all participants were informed the procedures of the study and signed a consent form prior to participation and they were able to withdraw of the study at any time without any consequences. They had no sports activity experienced within past three years. All of participants were female and they randomly placed into two groups named aquatic exercise $(n=19)$ and control $(n=20)$ groups. The aquatic group participated in 12 weeks aquatic exercise held at Sultan Idris Education University (UPSI) outdoor swimming pool from October to December 2018.

\section{Outcome measurements}

The modified Oswestry questionnaire (Bilingual; English-Malaysian Malay) was completed by all participants, one day before of the aquatic exercise program and one day after the last session as part of the posttest procedure. The modified Oswestry widely used measure of LBP disability which consists of 10 sections; pain intensity, personal care, lifting, walking, sitting, standing, sleeping, social life, traveling, and employment/homemaking (Ashraf et al., 2014; Mannion et al., 2006; McKillop et al., 2018). Each of the 10 sections is scored separately ( 0 to 5 points each) and then added up (maximum total $=50$ ). If all 10 sections are completed, simply double the patient's score (maximum total $=100$ ). The measurement of the weight, height, and BMI, waist to hip ratio (WHR) and percentage of body fat (PBF) were measured via InBody Scan 370 , body composition analyzer.

\section{Sample size}

The power of analysis was conducted by G*Power 3.0.10, which indicated a sample size of 18 would give $80 \%$ power for each variable while the sample for each group was 20 participants. 


\section{Aquatic exercise intervention program}

As an intervention program, a 12-week aquatic exercise was carried out two sessions weekly for $60 \mathrm{~min}$ per session. The aquatic exercise was conducted in shallow water (chest deep water; 120 $\mathrm{cm}$ and $150 \mathrm{~cm}$ in depth) and it was conducted under supervision of aquatic exercise therapist. It was concluded the static stretching of the hamstrings, calf, and upper and lower back muscles; 10-25 $\mathrm{m}$ front, back and sideways walking; 10-25 $\mathrm{m}$ front jogging; $15-20$ $\mathrm{m}$ with self-chosen speed, forward and side lunges, leg pedaling and cycling in supine position; self-chosen repetition, upper body mobilization and shoulder transvers exercise. Each exercise was repeated in three sets in each session (Olson et al., 2013; Rewald et al., 2016). The whole session required about $60 \mathrm{~min}$, which $10 \mathrm{~min}$ of warm-up, 40-min aquatic exercise, 5 min of cool-down and relaxation exercises, and 5-min self-care free water-activity were considered for each session of exercise (Fisken et al., 2015). An overview of program by details is shown in Table 1 .

The intensity and frequency of the exercise were gradually increased followed by the weeks and after week 3 the aquatic exer-

Table 1. Aquatic exercise program

\begin{tabular}{|c|c|c|}
\hline Exercise & & $\begin{array}{l}\text { Intensity \& frequency } \\
\text { (week } 1 \rightarrow \text { week 12) }\end{array}$ \\
\hline \multirow[t]{12}{*}{$\begin{array}{l}\text { Main exercise } \\
\text { (40 min) }\end{array}$} & $\begin{array}{l}\text { Water walking/ jogging (forward and } \\
\text { backward) }\end{array}$ & $\begin{array}{l}\text { Self- chosen speed } \\
10 \mathrm{~m} \times 4 \rightarrow 25 \mathrm{~m} \times 8\end{array}$ \\
\hline & Forward lunges & $\begin{array}{l}\text { Self-chosen rpm } \times 3 \\
\quad \rightarrow 10\end{array}$ \\
\hline & Side lunges & $\begin{array}{l}\text { Self-chosen rpm } \times 3 \\
\quad \rightarrow 10\end{array}$ \\
\hline & Supine position with hip and knee bent & $\begin{array}{l}\text { Self-chosen rpm } \times 3 \\
\quad \rightarrow 20 \times 6\end{array}$ \\
\hline & Supine position+leg pedaling & $\begin{array}{l}\text { Self-chosen rpm } \times 3 \\
\quad \rightarrow 20 \times 6\end{array}$ \\
\hline & Supine position+cycling & $\begin{array}{l}\text { Self-chosen rpm } \times 3 \\
\quad 5 \rightarrow 20\end{array}$ \\
\hline & $\begin{array}{l}\text { Shoulder transvers (abduction, } \\
\text { adduction, flexion and extension) }\end{array}$ & $\begin{array}{l}\text { Repeated slowly×3 } \\
\quad 6 \rightarrow 15\end{array}$ \\
\hline & $\begin{array}{l}\text { Upper body mobilization (with } \\
\text { kickboard) }\end{array}$ & $\begin{array}{l}\text { Self-chosen rpm } \times 3 \\
\quad \rightarrow 10\end{array}$ \\
\hline & Arm pendulum (in different intense) & $\begin{array}{l}\text { Repeated slowly } \times 3 \\
\quad 6 \rightarrow 15\end{array}$ \\
\hline & Deep water cycling (with woggle) & $30 \mathrm{sec} \rightarrow 1 \mathrm{~min} \times 3$ \\
\hline & Pool plank (with woggle) & $\begin{array}{l}\text { Self-chosen rpm } \times 3 \\
\quad 3 \rightarrow 10\end{array}$ \\
\hline & Wall push-up & $\begin{array}{l}\text { Self-chosen intense } \times 3 \\
\qquad 5 \rightarrow 10\end{array}$ \\
\hline $\begin{array}{l}\text { Warm-up } \\
\text { (10 min) }\end{array}$ & \multicolumn{2}{|c|}{$\begin{array}{l}\text { Static walk, combination of stretching exercise, water walking } \\
\text { for range of motion and relaxation }\end{array}$} \\
\hline $\begin{array}{l}\text { Cool-down } \\
\text { (10 min) }\end{array}$ & \multicolumn{2}{|c|}{$\begin{array}{l}\text { Stretching, deep breathing technique, relaxation and self-care } \\
\text { free water-activity }\end{array}$} \\
\hline
\end{tabular}

cise was performed at $150 \mathrm{~cm}$ in depth pool. In this depth of water, the participants performed the exercises (walking, jogging, pedaling, cycling, and relaxation) with swimming woggles, as the aid equipment. The conditioning of intensity was considered 1317 Borg Scale $(60 \%-70 \%)$ of their maximum heart rate (Rewald et al., 2016).

The devices that the participants used to assist them during exercises were swimming woggle, kickboard and Borg Scale. This intervention program conducted from October to December 2018 at UPSI outdoor swimming pool. Even though all sessions carried out at 5-6 p.m., the temperature of the pool was unable to maintain due to the weather changes. It should be declared that there was a replace session for the participants to fulfill two sessions exercise per week.

\section{Data analysis}

The data were collected via pre (before the intervention program) and posttest (after intervention program period) process. The mean and standard deviation for the demography data and LBP disability were analyzed using IBM SPSS Statistics ver. 23.0 (IBM Co., Armonk, NY, USA). One-way multivariate analysis of covariance (MANCOVA) was conducted to assess if there was difference between participants in the aquatic group and participants in the control group in the improvement of subsections of LBP disability after 12 weeks aquatic exercise. Since sample size of this study was less than 50, normality of data was verified using Shapiro-Wilk normality test, and also the variances for LBP disability between both groups assessed by using Levne test. The significance level was considered at $P \leq 0.05$.

\section{RESULTS}

Lastly, of the 40 enrolled participants, 19 of 20 in the aquatic exercise group and all of participants in the control group completed the posttest of Oswestry questionnaire. The reason for dropout from the aquatic exercise group was pregnancy $(n=1)$. According to the preliminary examination there was no significant difference between aquatic and control group participants in relation to their age, weight, height, BMI, WHR, and PBF, and both studied groups were statistically comparable. The average attendance of aquatic exercise group was $92 \%$ of aquatic exercise sessions during 12 weeks (24 sessions). It worth to remark that after session six of the program, the participants enthusiastically participated in the rest of exercise sessions regularly. In the control group, 15\% (three participants) of participants had physiotherapy exercise instruction, 
which was done irregularly at home, 15-20 min 2-3 times weekly. Even though the participants were in the control group, the researchers were not able to control all of their self-treatment conditions. The basic demographic data of each group shows in Table 2 . It should be mentioned that although the weight, BMI, WHR, and PBF of aquatic group after 3 months aquatic exercise inclined, the changes were statistically not significant.

Disability index of LBP in both groups and the frequency changes after 12 weeks aquatic exercise shows in Table 3. It should be mentioned that according to Oswestry score interpretation, people in minimal index can cope with most of their activities daily life and usually no treatment is needed, apart from advice on lifting, sitting, posture, physical fitness, and diet. In moderate index, individuals not only experiences more pain and problems with sitting, lifting, and standing, but travel and social life are more diffi-

Table 2. Demographic characteristics of participants for the aquatic and control groups

\begin{tabular}{lcccc}
\hline Variable & \multicolumn{2}{c}{ Aquatic $(\mathrm{n}=19)$} & \multicolumn{2}{c}{ Control $(\mathrm{n}=20)$} \\
\hline Age $(\mathrm{yr})$ & $37.85 \pm 5.83$ & $31-53$ & $40.8 \pm 5.25$ & $34-50$ \\
Height $(\mathrm{cm})$ & $157.3 \pm 6.17$ & $146-168$ & $156.8 \pm 4.53$ & $150-166$ \\
Pre-Weight $(\mathrm{kg})$ & $81.77 \pm 14.23$ & $65.4-116.3$ & $78.3 \pm 11.64$ & $65-104.3$ \\
Post-Weight $(\mathrm{kg})$ & $79.45 \pm 13.12$ & $63-110.6$ & $77.9 \pm 11.93$ & $65.3-106.1$ \\
Pre-Waist/Hip & $0.897 \pm 0.046$ & $0.832-1.01$ & $0.886 \pm 0.064$ & $0.83-1.104$ \\
Post-Waist/Hip & $0.896 \pm 0.041$ & $0.831-0.983$ & $0.887 \pm 0.069$ & $0.834-1.02$ \\
Pre-Body fat\% & $45.35 \pm 6.24$ & $34.6-54.5$ & $42.23 \pm 5.35$ & $36.10-56.30$ \\
Post-Body fat\% & $44.31 \pm 5.9$ & $34.0-53.40$ & $45.12 \pm 5.1$ & $36.50-56.23$ \\
Pre-Body mass index & $32.97 \pm 4.84$ & $27.22-41.98$ & $31.87 \pm 4.79$ & $28.13-45.33$ \\
Post-Body mass index & $32.08 \pm 4.47$ & $26.22-40.48$ & $31.71 \pm 4.92$ & $27.74-45.56$ \\
$\quad\left(\mathrm{~kg} / \mathrm{m}^{2}\right)$ & & & & \\
\hline
\end{tabular}

Values are presented as mean \pm standard deviation or range. cult and they may well be off work (Ashraf et al., 2014; Mannion et al., 2006). As Table 3 illustrates, the frequency of aquatic group participants in moderate index has reduced, after 12 weeks aquatic exercise, while in control group there are not notable changes in frequency of participants in moderate and minimal disability index.

Comparisons of disability scores as measured by 10 sections of Oswestry questionnaire, and statistically analyzed by MANCOVA for both groups after 12 weeks illustrates at Table 4 . No significant differences were found at baseline of lifting $(P<0.931)$, walking $(P<0.377)$, social life $(P<0.071)$, and traveling $(P<0.869)$, between both groups. The Bonferroni test data revealed a significant improvement in the pain intensity $(P<0.002)$, personal care $(P<$ $0.015)$, sitting $(P<0.004)$, standing $(P<0.006)$, sleeping $(P<0.022)$, and employment $(P<0.014)$ and total disability score $(P<0.020)$ of aquatic group after 12 weeks compared to the control group.

\section{DISCUSSION}

Considering the burden of LBP and its epidemiology in varieties of communities, this study aimed to investigate if a 12 week of aquatic exercise effect on the LBP disability among obese women

Table 3. Disability index according to group and tests in obese low-back pain women

\begin{tabular}{lccccc}
\hline \multirow{2}{*}{ Disability index } & \multicolumn{2}{c}{ Aquatic $(\mathrm{n}=19)$} & & \multicolumn{2}{c}{ Control $(\mathrm{n}=20)$} \\
\cline { 2 - 3 } \cline { 5 - 6 } & Baseline & Week 12 & & Baseline & Week 12 \\
\hline Minimal (0-20) & $2(10.5)$ & $16(84.2)$ & & $3(15)$ & $5(25)$ \\
Moderate (21-40) & $14(73.7)$ & $3(15.8)$ & & $15(75)$ & $13(65)$ \\
Severe (41-60) & $3(15.8)$ & - & & $2(10)$ & $2(10)$ \\
\hline
\end{tabular}

Values are presented as number (\%).

Table 4. Study arm data for disability scores and the subsections among obese low-back pain women $(n=39)$

\begin{tabular}{|c|c|c|c|c|c|c|c|}
\hline \multirow{2}{*}{$\begin{array}{l}\text { LBP disability } \\
\text { (Oswetry score*) }(0-5)\end{array}$} & \multicolumn{2}{|c|}{ Aquatic $(n=19)$} & \multicolumn{2}{|c|}{ Control $(n=20)$} & \multicolumn{3}{|c|}{ Group x time interaction effects } \\
\hline & Baseline & Week 12 & Baseline & Week 12 & $f$ & $P$-value & Eta $^{2}$ \\
\hline Pain Intensity & $2.21 \pm 1.27$ & $0.79 \pm 0.89$ & $2.05 \pm 1.10$ & $1.90 \pm 0.95$ & 9.370 & 0.002 & 0.540 \\
\hline Personal Care & $1.37 \pm 0.76$ & $0.32 \pm 0.48$ & $1.35 \pm 0.87$ & $1.05 \pm 0.76$ & 5.510 & 0.015 & 0.408 \\
\hline Lifting & $1.53 \pm 0.70$ & $0.68 \pm 0.48$ & $1.50 \pm 0.60$ & $1.35 \pm 0.58$ & 0.640 & 0.931 & 0.008 \\
\hline Walking & $1.25 \pm 0.99$ & $0.63 \pm 0.50$ & $0.85 \pm 0.59$ & $0.95 \pm 0.51$ & 1.037 & 0.377 & 0.115 \\
\hline Sitting & $1.89 \pm 1.10$ & $0.95 \pm 0.75$ & $1.70 \pm 0.81$ & $1.60 \pm 0.59$ & 8.190 & 0.004 & 0.506 \\
\hline Standing & $1.58 \pm 0.69$ & $0.53 \pm 0.51$ & $1.75 \pm 0.85$ & $1.60 \pm 0.68$ & 8.170 & 0.006 & 0.495 \\
\hline Sleeping & $1.21 \pm 0.97$ & $0.26 \pm 0.56$ & $1.00 \pm 0.88$ & $0.90 \pm 0.64$ & 4.980 & 0.022 & 0.379 \\
\hline Social Life & $1.26 \pm 0.65$ & $0.26 \pm 0.45$ & $1.30 \pm 0.57$ & $1.10 \pm 0.55$ & 3.120 & 0.071 & 0.281 \\
\hline Traveling & $1.47 \pm 0.84$ & $0.53 \pm 0.50$ & $1.35 \pm 0.81$ & $0.95 \pm 0.83$ & 0.142 & 0.869 & 0.017 \\
\hline Employment & $1.57 \pm 0.84$ & $0.53 \pm 0.61$ & $1.45 \pm 0.68$ & $1.50 \pm 0.60$ & 5.590 & 0.014 & 0.411 \\
\hline Disability Score (0-100) & $28.4 \pm 9.74$ & $12.42 \pm 5.40$ & $27.90 \pm 7.35$ & $26.4 \pm 7.56$ & 5.020 & 0.020 & 0.385 \\
\hline
\end{tabular}

Values are presented as mean \pm standard deviation. 
with nonsignificant chronic LBP. These findings revealed that a progressive intervention aquatic exercise program could be resulted to improve the LBP disability sections including pain intensity, personal care, and the ability of sitting, standing, sleeping and employment/homemaking in obese women. Meanwhile, no significant difference in lifting, walking, social life, and traveling abilities was found between the aquatic and control groups.

The findings of this study agree with Cuesta-Vargas et al.'s findings (Cuesta-Vargas et al., 2012). Similarly, in the study of Waller et al. (2009) advised therapeutic aquatic exercise not only can potentially be beneficial for pregnant patients who suffering from chronic LBP, but there are no any reports about a negative effect of aquatic exercise on LBP, also.

While Baena-Beato et al. (2013) found that aquatic therapy could reduce levels of back pain, disability and it subsequently enhanced quality of life, Intveld et al. (2010) explored aquatic physiotherapy on LBP cannot granted to improve pain intensity in pregnant participants, it is because of irregular physiotherapy sessions, which probably influence on their findings. Furthermore, there is some evidence to offer water-based exercise in order to assist the LBP individuals (Irandoust and Taheri, 2015; Olson et al., 2013; Waller et al., 2009), though they conducted in different methods and varied study groups.

However, the most important comprehensible reasoning to support this argument could be related to water properties that make exercise easier for obese LBP people. Firstly, the buoyancy of water can eliminate the gravitational forces to counteract body weight, which reduces the amount of joint stress to perform exercises with little effort and less pain sensation. It also can provide the greater range of movement that is required for lifting heaviest body limb or legs during exercise (Gordon and Bloxham, 2016; Louw et al., 2016; Waller et al., 2009). Secondly, viscosity of water increases resistance to allow strength exercise with gentle friction. Thirdly, since the water density is approximately 800 times more than air, combining the buoyancy and viscosity of water can interestingly provide a supreme source of resistance to improve muscle strength without bearing weight (Hossein Abadi et al., 2018). On the other hand, hydrostatic pressure utilizes forces perpendicular to the surface of body which results in reducing swelling, expanding joint position awareness and improving proprioception sense (Ariyoshi et al., 1999; Dundar et al., 2009). It can also be more motivated them to exercise without worrying about pain sensitivity in the water (Hossein Abadi et al., 2018).

Whereas gate control theory indicates that water-based exercise can probably improve muscle strength, muscle tension and mus- cle mass, and body pain release, aquatic exercise can play a more prominent role to rehabilitate obese people with LBP. Therefore, obese women can take part in aquatic exercises with more highintensity in water (Hossein Abadi et al., 2017), and they can also be more motivated to exercise without worrying about pain sensitivity (Shiri et al., 2010).

These findings are in line with previous studies with different water-based exercise intervention program that could recover pain intensty and musculoskeletal disability conditions in non-obese population (Barker et al., 2014; Karagülle and Karagülle, 2015). Furthermore, obese people who had further limitation on bearing weight and joint stress (Gordon and Bloxham, 2016) can perform exercise in water without high pressure, and expend higher energy effortlessly during a favorable exercise (Hossein Abadi et al., 2017). Although, these findings showed a significant improvement in pain intensity, personal care, and the ability of sitting, standing, sleeping and employment/homemaking, if individuals do not care their LBP seriously, the pain may continue, intensify could ultimately lead to disability (Shariat et al., 2019). In that, the effectiveness of this type of intervention also warrants investigation in future studies.

To conclude, a 12-week progressive aquatic exercise program can be more beneficial as a significant strategy to reduce pain intensity, and improve the abilities of personal care, sitting, standing, sleeping, and employment/homemaking among obese women with nonsignificant chronic LBP. But the significant evidence in the improvement of lifting, walking, social life, and traveling abilities is yet insufficient and not conclusive. Then another healthcare or lifestyle factors should be figured out to amend all sections of LBP disability. Further studies are needed to explore maintain of this program and follow up the period to validate the long-term of its effectiveness and reducing BMI, as well as more interestingly investigation about its effects on walking as an important daily activity among obese people with LBP.

\section{CONFLICT OF INTEREST}

No potential conflict of interest relevant to this article was reported.

\section{ACKNOWLEDGMENTS}

This study has been financially supported by University Research Grant code: 2018-0059-107-01 from Research Management and Innovation Centre, Sultan Idris Education. 


\section{REFERENCES}

Ariyoshi M, Sonoda K, Nagata K, Mashima T, Zenmyo M, Paku C, Takamiya $Y$, Yoshimatsu H, Hirai Y, Yasunaga H, Akashi H, Imayama H, Shimokobe T, Inoue A, Mutoh Y. Efficacy of aquatic exercises for patients with low-back pain. Kurume Med J 1999;46:91-96.

Ashraf A, Farahangiz S, Pakniat Jahromi B, Setayeshpour N, Naseri M. Correlation between degree of radiologic signs of osteoarthritis and functional status in patients with chronic mechanical low back pain. Malays J Med Sci 2014;21:28-33.

Baena-Beato PA, Arroyo-Morales M, Delgado-Fernández M, Gatto-Cardia MC, Artero EG. Effects of different frequencies (2-3 days/week) of aquatic therapy program in adults with chronic low back pain. A non-randomized comparison trial. Pain Med 2013;14:145-158.

Barker AL, Talevski J, Morello RT, Brand CA, Rahmann AE, Urquhart DM. Effectiveness of aquatic exercise for musculoskeletal conditions: a meta-analysis. Arch Phys Med Rehabil 2014;95:1776-1786.

Bender T, Karagülle Z, Bálint GP, Gutenbrunner C, Bálint PV, Sukenik S. Hydrotherapy, balneotherapy, and spa treatment in pain management. Rheumatol Int 2005;25:220-224.

Cuesta-Vargas AI, Adams N, Salazar JA, Belles A, Hazañas S, Arroyo-Morales $M$. Deep water running and general practice in primary care for non-specific low back pain versus general practice alone: randomized controlled trial. Clin Rheumatol 2012;31:1073-1078.

Delevatti R, Marson E, Fernando Kruel L. Effect of aquatic exercise training on lipids profile and glycaemia: a systematic review. Rev Andal Med Deport 2015;8:163-170.

Dundar U, Solak O, Yigit I, Evcik D, Kavuncu V. Clinical effectiveness of aquatic exercise to treat chronic low back pain: a randomized controlled trial. Spine (Phila Pa 1976) 2009;34:1436-1440.

Fisken A, Keogh JW, Waters DL, Hing WA. Perceived benefits, motives, and barriers to aqua-based exercise among older adults with and without osteoarthritis. J Appl Gerontol 2015;34:377-396.

Freburger JK, Holmes GM, Agans RP, Jackman AM, Darter JD, Wallace AS, Castel LD, Kalsbeek WD, Carey TS. The rising prevalence of chronic low back pain. Arch Intern Med 2009;169:251-258.

Gordon R, Bloxham S. A systematic review of the effects of exercise and physical activity on non-specific chronic low back pain. Healthcare (Basel) 2016;4(2):E22.

Hossein Abadi F, Choo LA, Sankaravel M, Mondam S. A comparative study of water and land based exercises training program on stability and range of motion. Int J Adv Res Technol 2018;7:68-72.

Hossein Abadi F, Elumalai G, Sankaraval M, Ramli FA. Effects of aquaaerobic exercise on the cardiovascular fitness and weight loss among obese students. Int J Physiother 2017;4:278-283.
Hoy D, Brooks P, Blyth F, Buchbinder R. The epidemiology of low back pain. Best Pract Res Clin Rheumatol 2010;24:769-781.

Intveld E, Cooper S, Van Kessel G. The effect of aquatic physiotherapy on low back pain in pregnant women. Int J Aquatic Res Educ 2010;4:5.

Ionescu DD, Ionescu AM, Jaba E. The investments in education and quality of life. J Knowl Manag Econom Inf Technol 2013;3:70.

Irandoust $\mathrm{K}$, Taheri $\mathrm{M}$. The effects of aquatic exercise on body composition and nonspecific low back pain in elderly males. J Phys Ther Sci 2015; $27: 433-435$

Karagülle M, Karagülle MZ. Effectiveness of balneotherapy and spa therapy for the treatment of chronic low back pain: a review on latest evidence. Clin Rheumatol 2015;34:207-214.

Lahiri S, Gold J, Levenstein C. Estimation of net-costs for prevention of occupational low back pain: three case studies from the US. Am J Ind Med 2005;48:530-541.

Lonik EAT, Kamauzaman THT, Abdullah AA, Nor J, Ab Hamid SA. Prevalence of low-back pain among public ambulance workers in Kelantan, Malaysia. Malays J Public Health Med 2017;17:126-135.

Louw A, Puentedura EJ, Zimney K, Schmidt S. Know Pain, Know Gain? A perspective on pain neuroscience education in physical therapy. J Orthop Sports Phys Ther 2016;46:131-134.

Mannion AF, Junge A, Fairbank JC, Dvorak J, Grob D. Development of a German version of the Oswestry Disability Index. Part 1: cross-cultural adaptation, reliability, and validity. Eur Spine J 2006;15:55-65.

McKillop AB, Carroll LJ, Dick BD, Battié MC. Measuring participation in patients with chronic back pain-the 5-Item Pain Disability Index. Spine J 2018;18:307-313.

Olson DA, Kolber MJ, Patel C, Pabian P, Hanney WJ. Aquatic exercise for treatment of low-back pain: a systematic review of randomized controlled trials. Am J Lifestyle Med 2013;7:154-160.

Piotrowska-Calka E. Effects of A 24-week deep water aerobic training program on cardiovascular fitness. Biol Sport 2010;27:95-98.

Rewald S, Mesters I, Lenssen AF, Emans PJ, Wijnen W, de Bie RA. Effect of aqua-cycling on pain and physical functioning compared with usual care in patients with knee osteoarthritis: study protocol of a randomised controlled trial. BMC Musculoskelet Disord 2016;17:88.

Shariat A, Alizadeh R, Moradi V, Afsharnia E, Hakakzadeh A, Ansari NN, Ingle L, Shaw BS, Shaw I. The impact of modified exercise and relaxation therapy on chronic lower back pain in office workers: a randomized clinical trial. J Exerc Rehabil 2019;15:703-708.

Shiri R, Karppinen J, Leino-Arjas P, Solovieva S, Viikari-Juntura E. The association between obesity and low back pain: a meta-analysis. Am J Epidemiol 2010;171:135-154.

Waller B, Lambeck J, Daly D. Therapeutic aquatic exercise in the treatment of low back pain: a systematic review. Clin Rehabil 2009;23:3-14. 